See Article page 114 .

\section{Commentary: Sometimes the best solution is to simplify}

\author{
Bahaaldin Alsoufi, MD
}

Luo and colleagues ${ }^{1}$ describe their modified 2-patch technique for the repair of supravalvular aortic stenosis. In their modification, the authors perform a transverse aortic incision above the sinotubular junction and then make 2 vertical incisions into the non- and right-coronary sinuses. These 2 incisions are extended superiorly into the ascending aorta, forming a final $\mathrm{H}$-like incision (hence the name H-repair). Following that, 2 separate rectangle-shaped pericardial patches are utilized to reconstruct the non- and rightcoronary sinuses, with the sizes of the distal patches adjusted to achieve normal sinotubular junction diameter. The purpose of this modification is to avoid kinking of the right coronary artery (RCA), usually the result of the oversized right coronary sinus patch in the traditional inverted Y 2-patch (Doty) repair. With the traditional repair, the authors report the incidence of RCA distortion at $27.3 \%$ (9 out of 33 ), whereas they report no RCA distortion in the 8 patients who received the H-repair. They conclude that the H-repair enlarges the aortic root while preserving RCA geometry and avoiding distortion. ${ }^{1}$

RCA distortion after surgical repair of supravalvular aortic stenosis is not fake news and I am well aware of such incidents occurring at institutions where I worked and anecdotally from various pediatric cardiac surgery colleagues. Oversizing of the patches, most importantly the right-coronary sinus patch, could result in RCA distortion and consequent ischemia. Naturally, infants might be

\footnotetext{
From the Department of Cardiovascular and Thoracic Surgery, University of Louisville School of Medicine, Norton Children's Hospital, Louisville, Ky.

Disclosures: The author reported no conflicts of interest.

The Journal policy requires editors and reviewers to disclose conflicts of interest and to decline handling or reviewing manuscripts for which they may have a conflict of interest. The editors and reviewers of this article have no conflicts of interest.

Received for publication Jan 6, 2021; revisions received Jan 6, 2021; accepted for publication Jan 11, 2021; available ahead of print Jan 13, 2021.

Address for reprints: Bahaaldin Alsoufi, MD, Department of Cardiovascular and Thoracic Surgery, University of Louisville School of Medicine, Norton Children's Hospital, 201 Abraham Flexner Way, Suite 1200, Louisville, KY 40202 (E-mail: balsoufi@hotmail.com).

JTCVS Techniques 2021;6:118-9

2666-2507

Copyright (c) 2021 The Authors. Published by Elsevier Inc. on behalf of The American Association for Thoracic Surgery. This is an open access article under the CC BY-NCND license (http://creativecommons.org/licenses/by-nc-nd/4.0/).

https://doi.org/10.1016/j.xjtc.2021.01.008
}

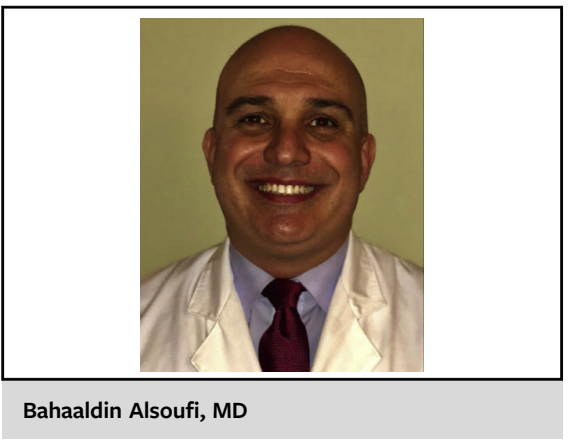

CENTRAL MESSAGE

Supravalvular aortic stenosis repair can result in right coronary distortion. Attention to patch size and geometry should decrease the incidence of this complication irrespective of repair strategy.

more susceptible to root geometric changes and subsequently RCA distortion. Although Luo and colleagues saw no such events with H-repair, their experience is obviously too small to prove superiority over traditional inverted Y 2-patch repair or the more elaborate 3-patch repair.

Irrespective of the type of repair performed, enlarging the root while being attentive to the configuration of the RCA is fundamental to avoiding this complication. There is a great element of art involved in congenital cardiac surgery, most specifically in vessel reconstruction and patching. Surgical experience and heightened awareness of this complication with thoughtful modeling of the patches could decrease the incidence of RCA distortion with any of these techniques. I am not sure that the report by Luo and colleagues is convincing enough to generate practice change among surgeons who utilize other surgical strategies.

Having been involved in the initial review of this submission, I witnessed the authors defending to some reviewers why they continue to use the 2-patch technique while the 3 -patch technique, which yields symmetric reconstruction, has demonstrated superiority over all other techniques..$^{2-4}$ This is obviously a rare lesion and single-institution series typically cover only a few dozen cases performed over multiple decades. Although surgeons might call various procedures that they perform by the same name, it is not unusual for there to be considerable variations among surgeons with fine technical modifications-again the element of 
art-that can lead to considerable differences despite the similar principle. These variations also explain the lack of consistency in the literature with some studies demonstrating superiority of 1 strategy over another and others finding comparable outcomes. ${ }^{2-6}$ I might belong to a small group of surgeons who have not found a considerable advantage to multisinus patching and continue to perform the simple single-patch repair to the noncoronary sinus, especially in infants who are theoretically at higher risk for RCA distortion and other complications. I am convinced that technical variations in singlepatch technique could affect the end result and the proximal and distal extensions of the aortic incisions, along with the width and configuration of the patch, play a role in early eradication of obstruction and later gradient across the reconstructed area.

In 2012, Kavarana and colleagues ${ }^{7}$ reported their experience with 22 children who underwent supravalvular aortic stenosis repair with extended single-patch technique. In their experience, an oblique aortic incision was made into the noncoronary sinus and extended superiorly toward the base of the innominate artery. A broad patch was then used to reconstruct the root and ascending aorta. They had no hospital deaths or incidence of RCA distortion and the gradients across the left ventricular outflow tract averaged $10 \pm 12 \mathrm{~mm} \mathrm{Hg}$ on midterm follow-up. That study highlights that differences in patch shape, size, and extension can lead to various results from the smaller, less-extensive traditional teardrop shape patch that was commonly used by surgeons in the past.
My experience with the extended single-patch technique is excellent. I believe this approach not only to be very effective in relieving supravalvular aortic stenosis with durable results, but also to be safe and associated with low likelihood of RCA distortion. Although few series have demonstrated higher residual gradients with the singlepatch approach, I believe that this strategy should be reexamined and that surgeons will find that the modified single-patch technique, which utilizes a broader and more extensive patch, might prove to be the simplest, quickest, and safest strategy while providing adequate and durable relief of supravalvular aortic stenosis that is comparable to more complex repair strategies.

\section{References}

1. Luo S, Haller C, Deng MX, Honjo O. H-repair in supravalvular aortic stenosis. J Thorac Cardiovasc Surg Tech. 2021;6:114-7.

2. Stamm C, Kreutzer C, Zurakowski D, Nollert G, Friehs I, Mayer JE, et al. Fortyone years of surgical experience with congenital supravalvular aortic stenosis. $J$ Thorac Cardiovasc Surg. 1999;118:874-85.

3. Metton O, Ben Ali W, Calvaruso D, Bonnet D, Sidi D, Raisky O, et al. Surgical management of supravalvular aortic stenosis: does Brom three-patch technique provide superior results? Ann Thorac Surg. 2009;88:588-93.

4. Kaushal S, Backer CL, Patel S, Gossett JG, Mavroudis C. Midterm outcomes in supravalvular aortic stenosis demonstrate the superiority of multisinus aortoplasty. Ann Thorac Surg. 2010;89:1371-7.

5. Hazekamp MG, Kappetein AP, Schoof PH, Ottenkamp J, Witsenburg M, Huysmans HA, et al. Brom's three-patch technique for repair of supravalvular aortic stenosis. J Thorac Cardiovasc Surg. 1999;118:252-8.

6. Fricke TA, d'Udekem Y, Brizard CP, Wheaton G, Weintraub RG, Konstantinov IE Surgical repair of supravalvular aortic stenosis in children with Williams syndrome: a 30-year experience. Ann Thorac Surg. 2015;99:1335-41.

7. Kavarana MN, Riley M, Sood V, Ohye RG, Devaney EJ, Bove EL, et al. Extended single-patch repair of supravalvular aortic stenosis: a simple and effective technique. Ann Thorac Surg. 2012;93:1274-8. 